\title{
Increase of Nocturnal Melatonin Levels in Hemodialyzed Patients after Parathyroidectomy - A Pilot Study
}

\author{
R. KANCHEVA ${ }^{1}$, S. SULKOVÁ ${ }^{2}$, F. ŠVÁRA ${ }^{3}$, M. HILL ${ }^{1}$, L. KANCHEV ${ }^{4}$, I. ŽOFKOVÁ ${ }^{1}$ \\ ${ }^{1}$ Institute of Endocrinology, Prague, ${ }^{2}$ Clinic of Gerontology and Metabolism, Division of \\ Nephrology, University Hospital of Charles University, Hradec Králové, ${ }^{3}$ Department of Internal \\ Medicine Strahov, General University Hospital, Prague, Czech Republic and ${ }^{4}$ New Bulgarian \\ University, Sofia, Bulgaria
}

Received November 12, 2007

Accepted January 28, 2008

On-line February 13, 2008

\section{Summary}

In hemodialyzed patients hormonal disturbances are known to occur. However, melatonin levels have not been completely studied. The aim of the study was to find whether changes in calcaemia affect melatonin secretion. For this reason we followed the nocturnal serum concentrations of melatonin and parathyroid hormone (PTH) in 9 hemodialyzed patients ( 6 women and 3 men, aged 37-65 years) both before and 1-3 months after parathyroidectomy at 6 p.m., 9 p.m., 11 p.m., 2 a.m., 5 a.m. and 7 a.m. At 6 p.m. blood samples to evaluate the levels of calcium and phosphate were also collected. Parathyroidectomy resulted in an increase in nocturnal melatonin levels. As expected, the parathyroidectomy was followed by considerable PTH decrease. PTH showed no nocturnal variation before or after parathyroidectomy. Calcium levels significantly decreased after the operation while phosphate levels increased. In summary, in hemodialyzed patients with hyperparathyroidism, parathyroidectomy significantly increases the nocturnal secretion of melatonin. Relationships between the pineal gland and parathyroid glands have yet to be elucidated.

\section{Key words}

Melatonin • Hemodialyzed patients - Hyperparathyroidism • Parathyroidectomy

\section{Corresponding author}

R. Kancheva, Institute of Endocrinology, Národní trída 8, 11694 Praha 1, Czech Republic. E-mail: rkanceva@endo.cz

\section{Introduction}

In hemodialyzed patients, hormonal disturbances are known to occur (Phocas et al. 1992, Weisinger et al. 2000). However, melatonin levels of these patients are not well studied. Melatonin plays a significant role and manifests a wide variety of actions on the organism. Diminished levels of melatonin are reported in some neurological and psychological disorders (Sanger et al. 2007), which also occur in hemodialyzed patients. In addition, patients with end-stage renal disease suffer from a number of related disorders. These include endocrine abnormalities, sleep disturbances, and depression. Melatonin is involved in the synchronization of exogenous zeitgebers with endogenous rhythms, and it has effects on various psychological factors (Fraschini et al. 1990, Illnerová et al. 2000, Ludemann et al. 2001). However, only a few studies have investigated the effect of dialysis on melatonin levels and the obtained results are conflicting. This is also valid in respect to the effect of parathyroidectomy on melatonin levels, i.e. limited number of studies with non-consistent results are available. That is why the authors tried to elucidate the effect of parathyroidectomy in hemodialyzed patients on nocturnal melatonin levels. According to the authors' knowledge there is no data available regarding this particular area of research. Further, it is also known that calcium influx is necessary for melatonin production (Zatz 1989). One would expect that the elevated levels of calcium (in hyperparathyroid patients on hemodialysis) and subsequently their decrease (after parathyroidectomy) 
Table 1. Values of the followed parameters before and after operation as well as their differences.

\begin{tabular}{lccccccc}
\hline & Before operation & After operation & $\begin{array}{c}\text { Difference } \\
\text { (After - before } \\
\text { operation) } \\
\text { mean } \pm \mathrm{SD}\end{array}$ & $\begin{array}{c}\text { Significance } \\
\text { of the } \\
\text { difference* }\end{array}$ \\
& $\mathrm{n}$ & mean $\pm \mathrm{SD}$ & $\mathrm{n}$ & mean $\pm \mathrm{SD}$ & $\mathrm{n}$ & \\
\hline PTH $(\mathrm{ng} / \mathrm{l})$ & 9 & $1187 \pm 626$ & 9 & $33.73 \pm 28.75$ & 9 & $-1154 \pm 631.1$ & $\mathrm{p}<0.01$ \\
Melatonin $(\mathrm{ng} / \mathrm{l})^{*}$ & 9 & $29.17 \pm 27.33$ & 9 & $53.19 \pm 40.71$ & 9 & $24.02 \pm 28.82$ & $\mathrm{p}<0.05$ \\
$\mathrm{Ca}^{2+}(\mathrm{mmol} / \mathrm{l})$ & 9 & $2.456 \pm 0.27$ & 9 & $1.978 \pm 0.335$ & 9 & $-0.48 \pm 0.211$ & $\mathrm{p}<0.01$ \\
$\mathrm{PO}_{4}{ }^{2-}(\mathrm{mmol} / \mathrm{l})$ & 9 & $1.733 \pm 0.361$ & 9 & $2.278 \pm 0.529$ & 9 & $0.544 \pm 0.648$ & $\mathrm{p}<0.04$ \\
\hline
\end{tabular}

${ }^{*}$ Wilcoxon paired robust test

might influence the levels of melatonin.

\section{Methods}

\section{Subjects}

Nine hemodialyzed patients with hyperparathyroidism participated in the study. They were: 6 women and 3 men, aged 37-65 years. None of them smoked at least one month before the blood withdrawals. All of the participants were fully informed about the purpose of the study and gave their written informed consent to participate. The trial was performed with the approval of the local Ethics Committee of the Institute of Endocrinology in Prague.

\section{Protocol}

Two profiles of nocturnal melatonin and parathyroid hormone were performed on each participant, i.e. before and 1-3 months after parathyroidectomy. In addition, serum levels of calcium and phosphate were followed twice- before and after the operation. The patients had a light meal at 5 p.m. and the test began at 6 p.m. The participants were advised to rest in a supine position for an hour in a quiet, dark room. During this period a venous catheter was placed into their cubital vein. Blood samples for estimation of melatonin and parathyroid hormone (PTH) were collected at 6 p.m., 9 p.m., 11 p.m., 2 a.m., 5 a.m. and 7 a.m. At 6 p.m. blood samples to evaluate the levels of calcium and phosphate were taken too. The blood withdrawals were carried out under a red lamp.

\section{Analytical methods}

Melatonin levels were determined by slight modifications of the RIA method of (Fraser et al. 1983). The buffer (Tricine $0.1 \mathrm{M}, \mathrm{pH} 5.0$ ) in addition to 0.1 gelatine and $0.14 \mathrm{M} \mathrm{NaCl}$, contained $5 \mathrm{mM}$ EDTA, $0.1 \%$ BSA and $0.01 \%$ human gamma globulin. Sheep antimelatonin antibody (batch No 704-8483) was obtained from Guildhay (University of Surrey, Surrey, U.K.) The assay parameters were as follows: sensitivity $3.0 \mathrm{pg} /$ tube, slope of the curve 1.1, intra- and inter-assay coefficients of variation $7.0 \%$ and 10.2 , respectively. In respect to PHT, an Allegro Intact PTH commercial kit from the Nichols Institute, San Juan Capistrano, CA, USA was applied. With regard to serum minerals, a Merck Autoanalyzer was used. The inter-assay coefficients of variation were as follows: $5.8 \%$ for PTH, 5.7 for calcium and $6.4 \%$ for phosphate, while the intra-assay coefficients of variation were: $3.0 \%$ for PTH, $3.6 \%$ for calcium and $4.2 \%$ for phosphate.

\section{Statistical data analysis}

Nocturnal profiles of melatonin and PTH were evaluated by repeated measures ANOVA followed by least significant difference multiple comparisons. The ANOVA model consisted of within-subject factors: Operation (before, after) and Hour (hour when the sample was withdrawn), interaction Operation $\times$ Hour, and subject factor separating the inter-individual variability from variability connected with remaining factors and the interaction. Due to non-Gaussian data distribution, the variables were treated by a power transformation to attain symmetric distribution and constant variance (Meloun et al. 2000, 2002). Outliers were searched using residual analysis. However, the data contained no outliers when using power transformations. The differences in calcium and phosphate levels at the beginning of the daily profile 


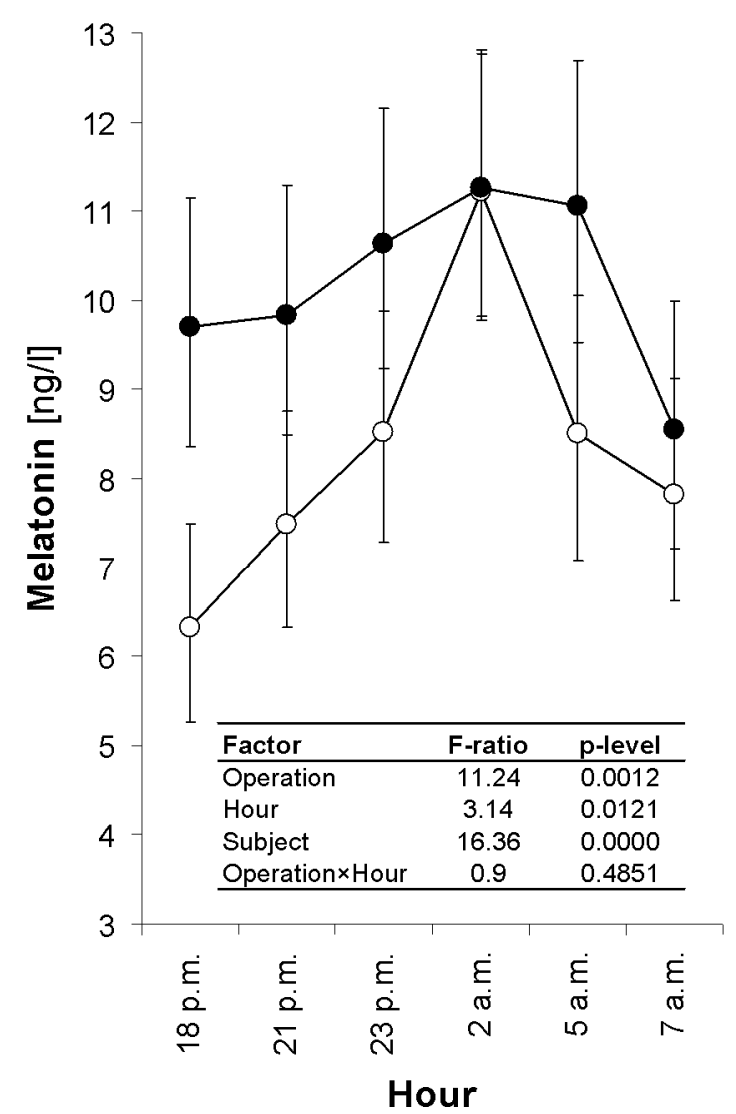

Fig. 1. Nocturnal profiles of melatonin in hemodialyzed patients before and after parathyroidectomy evaluated by repeated measures ANOVA consisting of Operation (before, after) and Hour within-subject factors, subject factor, and Operation $\times$ Hour interaction. The empty and full circles represent re-transformed mean melatonin levels with their $95 \%$ confidence intervals for individual hours of the trial before and after parathyroidectomy, respectively.

before and after the operation were evaluated by paired Student's t-test or robust paired Wilcoxon's test depending on symmetry of data distribution.

\section{Results}

Nocturnal profiles of melatonin before and after parathyroidectomy showed significant time dependence (F-ratio $=3.14, \mathrm{p}<0.02$, ANOVA). This dependence was much weaker when the effect of parathyroidectomy was taken into account (Fig. 1, Table 1). The operation resulted in a significant increase in nocturnal melatonin levels (F-ratio=11.2, $\mathrm{p}<0.002$, ANOVA). As expected, the parathyroidectomy was followed by radical PTH decrease (F-ratio $=682, \quad \mathrm{p}<0.0001, \quad$ ANOVA). PTH showed no nocturnal variation both before and after the parathyroidectomy (Fig. 2, Table 1). Calcium and phosphate were measured before and after parathyroidectomy each time at the beginning of blood

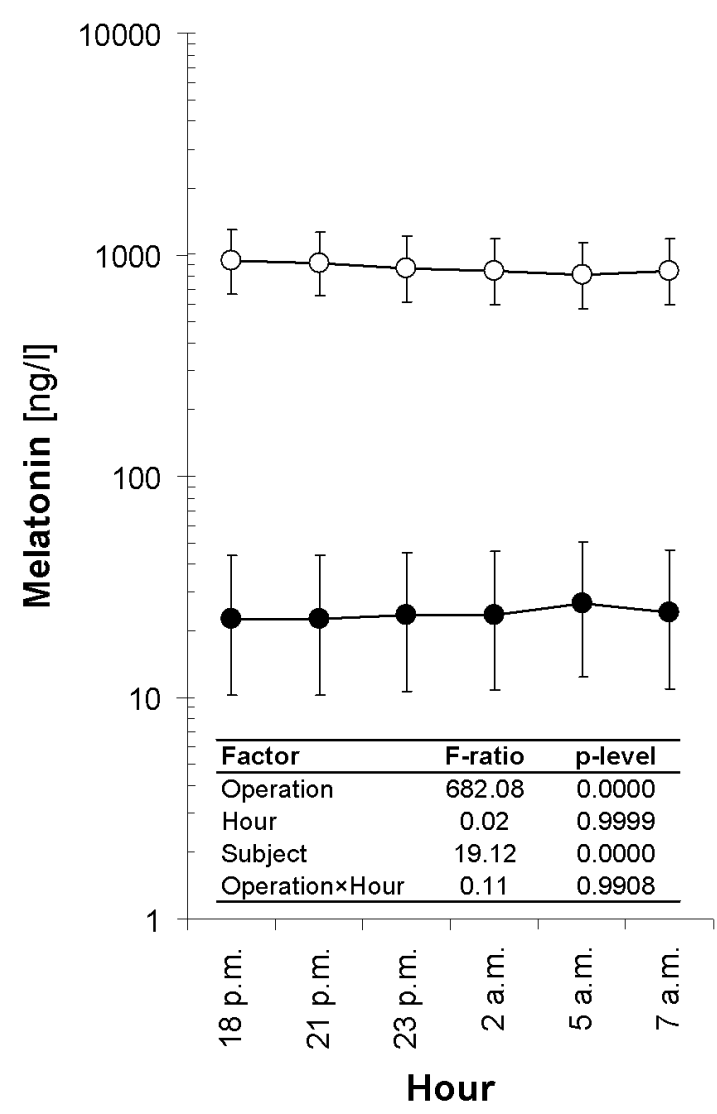

Fig. 2. Nocturnal profiles of PTH in hemodialyzed patients before and after parathyroidectomy. The drawings and symbols are the same as in Fig. 1.

sampling. Calcium significantly decreased $(\mathrm{p}<0.001$, Student's paired t-test) (Fig. 3A, Table 1) after operation while phosphate levels increased (Fig. 3B, Table 1) $(p<0.05$, Wilcoxon's robust paired t-test).

\section{Discussion}

In spite of the fact that hormonal disturbances are known occurrences in patients with end-stage renal failure, studies on the function of melatonin have not yielded much information about the relationships between this hormone and kidneys in health, and particularly, in disease. Little is known about circadian melatonin concentrations in patients with chronic renal failure. There are a few studies which were mainly performed in hemodialyzed patients. Moreover, most melatonin assays are performed during the daytime, and the results are conflicting. Ludemann et al. (2001) reported that mean melatonin levels not only before but also after hemodialysis in hemodialyzed patients were highly elevated when compared with the melatonin levels of controls. On the contrary, Karasek el al. (2002, 2005) discovered diminished melatonin levels in patients with 
A

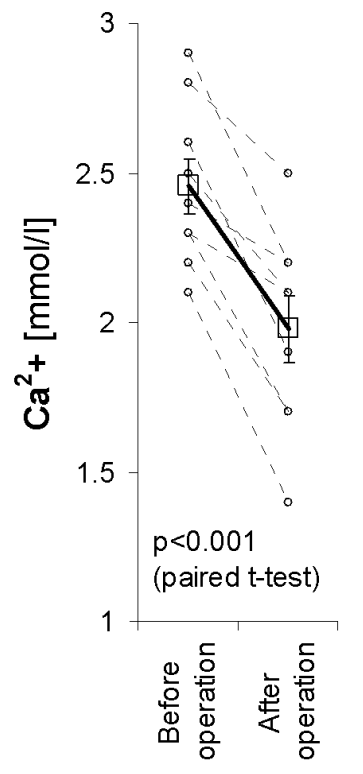

B

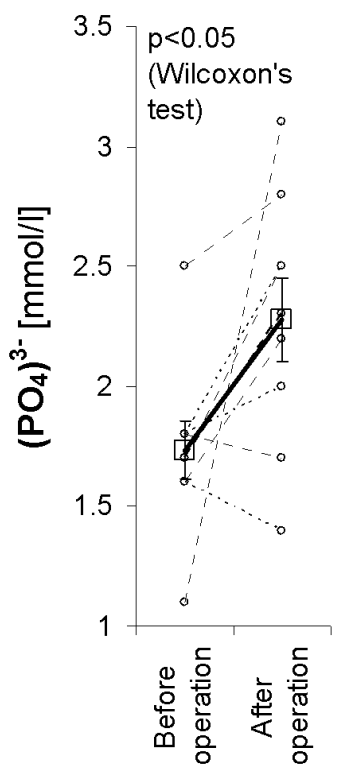

Fig. 3. Changes in serum levels of calcium (section $A$ ) and phosphate (section B) after parathyroidectomy. Circles represent experimental points while the squares with error bars represent means \pm S.E.M.

chronic renal disease undergoing hemodialysis in comparison with levels in healthy controls. One of the possible explanations for the latter findings is that the decline in melatonin levels is due to impairment in adrenergic function that occurs in chronic renal failure (Karasek et al. 2002).

A further factor which might influence melatonin levels is parathyroid hormone. Results concerning the effect of parathyroidectomy and its impact on melatonin levels are also inconsistent. Abdel-Wanis et al. (2001) first described in the literature a case of coexisting neurofibromatosis, primary hyperparathyroi-

dism due to parathyroid adenoma and osteomalacia. The authors also reported a drop in melatonin level after parathyroidectomy. On the other hand, when Chou et al. (2005) investigated the levels of melatonin after parathyroidectomy due to secondary hyperparathyroidism in thirty-one patients, the authors found no changes in nocturnal melatonin levels one week after parathyroidectomy.

The results of our study established increased nocturnal melatonin levels in hemodialyzed patients one to three months after parathyroidectomy. All of the aforementioned trials in the discussion investigated melatonin levels in hemodialyzed patients or in patients after parathyroidectomy (due to primary or secondary hyperparathyroidism) but not the combination of haemodialysis and parathyroidectomy (due to tertiary hyperparathyroidism). An additional difference was that only nocturnal melatonin levels were measured in our study.

In summary, in hemodialyzed patients with hyperparathyroidism, parathyroidectomy significantly increases the nocturnal secretion of melatonin. Relationships between the pineal gland and parathyroid glands have yet to be elucidated in larger group of individuals.

\section{Conflict of Interest}

There is no conflict of interest.

\section{Acknowledgements}

The study was supported by Research Project IGA No NR/9157-3 from the Ministry of the Health of the Czech Republic and MSM0021620819.

\section{References}

ABDEL-WANIS ME, KAWAHARA N, TOMITA K: The association of neurofibromatosis 1 and spinal deformity with primary hyperparathyroidism and osteomalacia: might melatonin have a role? J Orthop Sci 6: 193-198, 2001.

CHOU FF, LEE CH, CHEN JB, HUANG SC, LEE CT: Sleep disturbances before and after parathyroidectomy for secondary hyperparathyroidism. Surgery 137: 426-430, 2005.

FRASCHINI F, SCAGLIONE F, FRANCO P, DEMARTINI G, LUCINI V, STANKOV B: Melatonin and immunity. Acta Oncol 29: 775-776, 1990.

FRASER S, COWEN P, FRANKLIN M, FRANEY C, ARENDT J: Direct radioimmunoassay for melatonin in plasma. Clin Chem 29: 396-397, 1983.

ILLNEROVÁ H, SUMOVÁ A, TRÁVNÍČKOVÁ Z, JÁČ M, JELÍNKOVÁ D: Hormones, subjective night and season of the year. Physiol Res 49 (Suppl 1): S1-S10, 2000.

KARASEK M, SZUFLET A, CHRZANOWSKI W, ZYLINSKA K, SWIETOSLAWSKI J: Circadian serum melatonin profiles in patients suffering from chronic renal failure. Neuroendocrinol Lett 23 (Suppl 1): 97-102, 2002. 
KARASEK M, SZUFLET A, CHRZANOWSKI W, ZYLINSKA K, SWIETOSLAWSKI J: Decreased melatonin nocturnal concentrations in hemodialyzed patients. Neuro Endocrinol Lett 26: 653-656, 2005.

LUDEMANN P, ZWERNEMANN S, LERCHL A: Clearance of melatonin and 6-sulfatoxymelatonin by hemodialysis in patients with end-stage renal disease. J Pineal Res 31: 222-227, 2001.

MELOUN M, HILL M, MILITKÝ J, KUPKA K: Transformation in the PC-aided biochemical data analysis. Clin Chem Lab Med 38: 553-559, 2000.

MELOUN M, MILITKY J, HILL M, and BRERETON R G: Crucial problems in regression modelling and their solutions. Analyst 127: 433-450, 2002.

PHOCAS I, SARANDAKOU A, KASSANOS D, RIZOS D, TSERKEZIS G, KOUTSIKOS D: Hormonal and ultrasound characteristics of menstrual function during chronic hemodialysis and after successful renal transplantation. Int J Gynecol Obstet 37: 19-28, 1992.

SANGER DJ, SOUBRANE C, SCATTON B: New perspectives for the treatment of disorders of sleep and arousal. Ann Pharm Fr 65: 268-274, 2007.

WEISINGER JR, GONZALEZ L, ALVAREZ H, HERNANDEZ E, CARLINI RG, CAPRILES F, CERVINO M, MARTINIS R, PAZ-MARTINEZ V, BELLORIN-FONT E: Role of persistent amenorrhea in bone metabolism of young hemodialyzed women. Kidney Int 58: 331-335, 2000.

ZATZ M: Relationship between light, calcium influx and cAMP in the acute regulation of melatonin production by cultured chick pineal cells. Brain Res 477: 14-18, 1989. 